\title{
The Nursing Strategies of Hip Joint Arthroplasty for Dialysis-Dependent Patients
}

\author{
Hongxia Zhu ${ }^{1}$, Lunli Xie ${ }^{2}$, Hui Yang ${ }^{2}$, Jie Zhang ${ }^{2}$, Yuyan Xie ${ }^{1}$, Lizhen Liư ${ }^{1}$, Jichun Yang and Dan Pu ${ }^{2 *}$ \\ ${ }^{1}$ Department of Traumatic Orthopaedics, The First People's Hospital of Huaihua, China \\ ${ }^{2}$ Department of Minimally Invasive Orthopaedics, The First People's Hospital of Huaihua , China
}

Submission: October 15, 2018; Published: October 29, 2018

*Corresponding author: Dan Pu, Department of Minimally Invasive Orthopaedics, Department of Rehabilitation Medicine Center, The First People's Hospital of Huaihua (Jishou university of the fourth affiliated hospital), China.

Keywords: Uremia; Arthroplasty; Nursing strategies; Hemiarthroplasty; Nephropathy

\section{Introduction}

It is a meaning to accept regular dialysis treatment for patient with uremia. However, dialysis-dependent patients frequently develop osteoarthritis or osteonecrosis that warrants joint arthroplasty [1]. Many studies described Nursing Strategies and Managements for hip replacement but may not reflect standard for this dialysis-dependent patient [2,3]. Besides, no consensus has been reached to this especial populations at present. This paper reports the perioperative nursing strategies for two dialysis-dependent patients who accepted hemiarthroplasty in order to share clinical and nursing experience.

\section{The Clinical Data}

In the databases, we identified 2 dialysis-dependent patients (Female/Male:1:1) who had undergone hemiarthroplasty from 2017 through 2018 and performed analysis nursing strategies in perioperative period. Respectively, uremia was caused by Diabetic Nephropathy and Chronic Glomerulonephritis. There was no history of allergy to medications or of any previous anesthesiarelated problems. Otherwise, there were no complications of hypersplenism, thrombocytopenia, pulmonary infection, and heart failure. The female patient occurred spontaneous periprosthetic fractures on postoperative days 7 and she accepted conservative treatment. No other complication occurred in follow-up period (6 months).

\section{The Nursing Strategies}

The Nursing Strategies includes the health education, muti-disciplinary treatment, regular hemodialysis, nursing for endovascular fistula, pain management, and other comprehensive management in perioperative period (Figure 1) (Table 1).

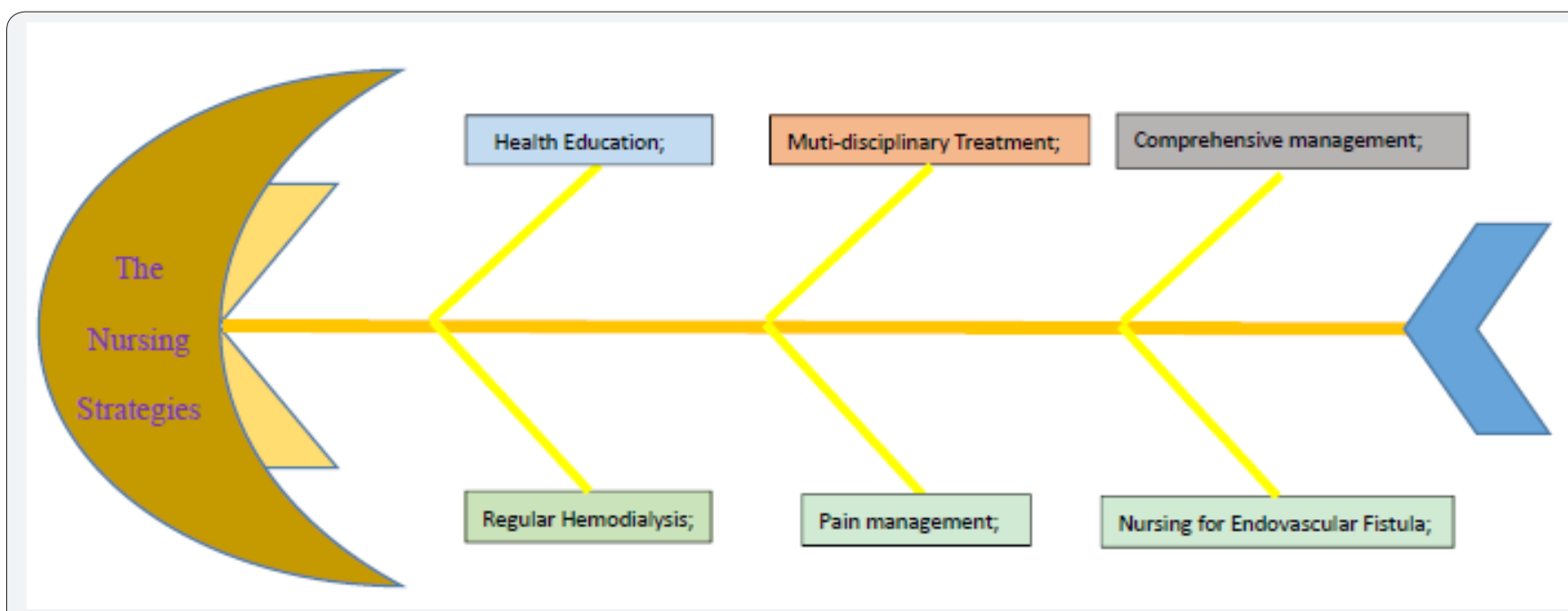

Figure1: This Fish-bone diagram illustrates the nursing strategies for dialysis-dependent patient who accepted hip arthroplasty. These strategies include the health education, muti-disciplinary treatment, regular hemodialysis, nursing for endovascular fistula, pain management, and other comprehensive management in perioperative period. 


\section{Palliative Medicine and Care International Journal}

Table 1: Nursing Strategies of Hip Joint Arthroplasty in Dialysis-Dependent Patient.

\begin{tabular}{|c|c|c|}
\hline Items & Summary and Recommendation & \\
\hline \multirow{7}{*}{ Health Education } & $\begin{array}{c}\text { The high-quality proteins, high calories and high vitamin diet and eternal nutrition ap- } \\
\text { proval, professional nursing steps. }\end{array}$ & Dietary Management \\
\hline & $\begin{array}{l}\text { Avoiding to use high salt and potassium food and monitoring the glucose levels for the } \\
\text { diabetic. }\end{array}$ & Dietary Management \\
\hline & The perioperative period is $6 \mathrm{hrs}$ for liquids and $8 \mathrm{hrs}$ for solid food. & Dietary Management \\
\hline & The suitable body positions and functional training. & Exercise Missionary \\
\hline & The muscle strengthening and its range of motion training. & Exercise Missionary \\
\hline & $\begin{array}{c}\text { The explanation of the disease with its characteristics, progression, and knowledge of } \\
\text { surgeries. }\end{array}$ & Psychological Counseling \\
\hline & The management of mood and ease anxiety. & Psychological Counseling \\
\hline \multirow[t]{2}{*}{$\begin{array}{l}\text { Muti-disciplinary } \\
\text { Treatment }\end{array}$} & $\begin{array}{l}\text { The multidisciplinary consultations include nephrology, hematology, anesthesiology, endo- } \\
\text { crinology, and blood dialysis room. }\end{array}$ & $\begin{array}{l}\text { Multidisciplinary Consul- } \\
\text { tations }\end{array}$ \\
\hline & The team consists of physician, nurse and rehabilitation therapist. & Professional Team \\
\hline \multirow{4}{*}{$\begin{array}{l}\text { Comprehensive Man- } \\
\text { agements }\end{array}$} & Concerning the oxyhemoglobin saturation, blood pressure, and pain. & Vital sign monitoring \\
\hline & Communication with surgeon about the results of laboratory investigations. & $\begin{array}{l}\text { Analysis of biomedical } \\
\text { reports }\end{array}$ \\
\hline & $\begin{array}{l}\text { The application of low molecular weight heparin per day and functional training for unin- } \\
\text { jured limb. }\end{array}$ & Prophylactic Anticoagulant \\
\hline & The guidance of usage of bedpan and basic skill training. & Lifestyle Guidance \\
\hline \multirow[t]{3}{*}{ Regular Hemodialysis } & $\begin{array}{l}\text { The adjustment of hemodialysis basing on the results of levels of creatinine and urea } \\
\text { nitrogen in blood. }\end{array}$ & Effective Hemodialysis \\
\hline & Proper training of upper limb with AVG. & Observation of Permeability \\
\hline & Regular observation by means of echo meter. & Regular Observation \\
\hline \multirow{2}{*}{$\begin{array}{l}\text { Endovascular Fistula } \\
\quad \text { Nursing }\end{array}$} & Avoiding to low blood pressure and dehydration. & Maintaining and Monitoring \\
\hline & Prohibition of any intervention with or without invasive action in upper limb with AVG. & Prohibition Action \\
\hline \multirow{2}{*}{ Pain Management } & The usage of the NIASDs or Opioid drugs basing on evaluation of pain such as VAS. & Drugs Controlling \\
\hline & $\begin{array}{l}\text { By means of the rehabilitation therapies includes electropuncture and audio frequency } \\
\text { electricity }\end{array}$ & Physiotherapy Assistance \\
\hline
\end{tabular}

\section{Discussion}

\section{Effective Health Education}

The contents of health education include dietary management, exercise missionary, and psychological counseling. It may be better to select the absorbable foods with high-quality proteins, high calories, and high vitamin, but low in salt and potassium [4]. Besides, in particular salt and protein restriction are fundamental for the proper care of CKD patients [5]. At the same time, the glucose levels should also be paid attention for the patients with diabetes [6]. Obviously, the suitability of the preoperative fasting and water-deprivation concentration may be preventing to situation of vomit and aspiration. Additionally, emphasizing proper body positions and effective functional training, which are important parts of the nursing managements in perioperative period. The muscle strengthening, and its range of motion will be encouraged to perform for the patient without any contraindications [7]. Notably, there is same importance of psychological counseling in these population. The positive mood management is viewed as work of psychological counseling in this patient, which needs the nurse to explain this disease with its characteristics, progression, and knowledge of surgeries;
Moreover, the sufficient communication and correct guidance may also show supplement for treatment [8].

\section{Muti-Disciplinary Treatment}

The researcher's provider plan that the individualized therapeutic protocol and evaluation of risks as the part of Muti-disciplinary treatments, which are basing on the medical records and advice of specialist consultation [9]. In regard to the dialysis-dependent patient, muti-disciplinary strategies include nephrology, hematology, anesthesiology, endocrinology, and blood dialysis room. The intensive care unit (ICU) can provider special treatments for postoperative period. In addition to, the team consists of physician, nurse, and rehabilitation therapist that may make supplements of treatments for the dialysis-dependent patients [10]. It is unique way to combine the specific nursing and enhanced recovery after surgery basing on the physical condition [11].

\section{Other Comprehensive Management in Perioperative Period}

The comprehensive managements consist of vital sign monitoring, analysis of biomedical reports, cough training and defecation habit practice, usage of antibiotics, and prophylactic anti- 
coagulant [12]. Regularly, to monitor oxyhemoglobin saturation, blood pressure, and pain that should be viewed as a part of the general nursing works. There are benefits for recovery, when the nurse pays attention to results of laboratory investigations and communicate with physician. The ways of using bedpan and to combine with the purgative are illustrated by nurses. Avoiding using cephalosporin antibiotics or drugs with renal toxicity results in drug-induced encephalopathy. The reasonable strategies of prophylactic anticoagulant including physical nursing of active or passive measures and preventive anticoagulant treatment by low molecular weight heparin or a hybrid approach ask nurse to perform dynamic evaluation and systematic nursing education [13].

\section{Regular Hemodialysis}

All patients accepted heparin free dialysis before surgery day 1 aiming to reducing levels of creatinine and urea nitrogen in blood. Some authors indicated that the surgery can be performed as scheduled if the concentrations of creatinine under $445 \mathrm{umol} / \mathrm{L}$ and the levels of urea nitrogen are inferior to $20 \mathrm{mmol} / \mathrm{L}$ in blood on surgerical day $[14,15]$. At the same time, maintaining the concentrations of potassium ion less than $4.5 \mathrm{mmol} / \mathrm{L}$ shows advantage for surgery. Last but not least, the hemodialysis should follow the rationale of strategies as preoperative action, but it is essential to monitor concentration of creatinine, urea nitrogen, and potassium ion in blood.

\section{Nursing for Endovascular Fistula}

Internal arteriovenous fistula (AVG) as the measurements of long-term hemodialysis that shows its importance for uremia patient. The careful observation and nursing protection of AVG and the preventive embolisms show its significance in nursing works [16]. The permeability of AVG can be performed assessment according to the following criterion:

i. $\quad$ Proper training and raising of upper limb;

ii. Regular observation by means of echo meter;

iii. Avoiding to low blood pressure and dehydration;

iv. Prohibition of any noninvasive or invasive intervention in upper limb with AVG.

\section{Pain Management}

Some published articles revealed the fact that pain management is essential for patients accepted joint replacement $[17,18]$. Suitable and effective measures of pain management may provider the benefit for recovery and high quality of hospital life. Not only the drugs are used to kill pain, but also the rehabilitation therapies such as the rehabilitation therapies includes electropuncture and audio frequency electricity are used for relieving pain. At the same time, the evaluation of pain by terms of Visual Analogue Scale (VAS) can help physician to adjust strategies of pain management.

\section{Conclusion}

In our paper, the nursing strategies provider a series of clinical nursing experiences. The limitations of our study are related to retrospective cases analysis, and without control group. Besides, there are only two cases without enough data supporting these nursing strategies for the end-stage renal disease receiving chronic dialysis. In conclusion, the hip joint arthroplasty is much higher-risk endeavors in dialysis-dependent patients. And the effective nursing strategies can show the benefits for treatments.

\section{Funding}

The Scientific and Innovative Research Foundation of Hunan Province (CX2016B617); the Scientific Program of the Heath and Family Planning Commission of Hunan Province (C2016129)

\section{Conflict of Interest}

No potential conflict of interest relevant to this article was report.

\section{References}

1. Tosun B, Atmaca H, Gok U (2010) Operative treatment of hip fractures in patients receiving hemodialysis. Musculoskeletal Surgery 94(2): 71 75.

2. Herfjord JK, Heggestad T, Ersland H, Ranhoff AH (2014) Intermediate care in nursing home after hospital admission: a randomized controlled trial with one year follow-up. BMC Research Notes 7(1): 889-889.

3. Issa K, Banerjee S, Rifai A, Kapadia BH, Harwin SF, et al. (2013) Blood management strategies in primary and revision total knee arthroplasty for Jehovah's Witness patients. Journal of Knee Surgery 26(6): 401404 .

4. Iseki K, Yamagata K (2016) A practical approach of salt and protein restriction for CKD patients in Japan. BMC Nephrology, 17(1): 87.

5. Pisani A, Riccio E, Bellizzi V, Caputo DL4, Mozzillo G, et al. (2016) 6-tips diet: a simplified dietary approach in patients with chronic renal disease. A clinical randomized trial. Clinical and Experimental Nephrology 20(3): 433-442.

6. Ricks J, Molnar MZ, Kovesdy CP, Shah A, Nissenson AR, et al. (2012) Glycemic Control and Cardiovascular Mortality in Hemodialysis Patients With Diabetes: A 6-Year Cohort Study. Diabetes 61(3): 708715.

7. Skoffer B, Dalgas U, Mechlenburg I (2015) Progressive resistance training before and after total hip and knee arthroplasty: a systematic review. Clinical Rehabilitation 29(1):14-29.

8. McDonald S, Page MJ, Beringer K, Wasiak J, Sprowson A (2014) Preoperative education for hip or knee replacement. Cochrane Database Syst Rev (5): CD003526.

9. Richard HM, Nguyen DC, Podeszwa DA, et al. (2018) Perioperative Interdisciplinary Intervention Contributes to Improved Outcomes of Adolescents Treated With Hip Preservation Surgery. J Pediatr Orthop 38(5): 254-259.

10. Yu Xie, XuBiao Ma, LunLi Xie, Jian Li, Jun Zhu, et al. (2018) Management Strategies for Femoral Head Replacement Arthroplasty in Uremia Patients: Case Report. Biomed J Sci \&Tech Res 4(1): 1-4.

11.Zhang Xiaoyan, Wu Xuyi (2015) Effects of integration of medical treatment and care-giving on patients' rehabilitation after hip replacement. Modern Clinical Nursing 14(10): 25-28.

12. Lucas B (2008) Total hip and total knee replacement: postoperative nursing management. Br J Nurs 17(21): 1346-1351.

13. Ding G, Li S, Pan Z, Goa C, Ma H (2014) Effects of batroxobin on perioperative blood loss and coagulation in patients with low molecular weight heparin when undergoing the total hip replacement. Zhonghua Liu Xing Bing Xue Za Zhi 35(6): 737-740. 
14. Lieu D, Harris IA, Naylor JM, Mittal R (2014) Total hip replacement in haemodialysis or renal transplant patients. J Orthop Surg (Hong Kong) 22(3): 393-398

15. Shi XJ, Zhou ZK, Shen B (2013) Perioperative Management of Patients with Chronic Kidney Dysfunction for Arthroplasty. Journal of Practical Orthopaedics 19(12): 1091-1093.

16. Zhang Zuping, Wang Xiaoping, Jin Fang, et al. (2013) Nursing Experience of High Internal Arteriovenous Fistula for Patients with Chronic
Hemodialysis. Western Journal of Traditional Chinese Medicine 3(26): 117-118.

17. Young AC, Buvanendran A (2014) Pain management for total hip arthroplasty. J Surg Orthop Adv 23(1): 13-21.

18. Sun L, Zhu X, Zou J, Li Y, Han W (2018) Comparison of intravenous and oral acetaminophen for pain control after total knee and hip arthroplasty: A systematic review and meta-analysis. Medicine (Baltimore) 97(6): e9751.

\section{Your next submission with Juniper Publishers will reach you the below assets}

- Quality Editorial service

- Swift Peer Review

- Reprints availability

- E-prints Service

- Manuscript Podcast for convenient understanding

- Global attainment for your research

- Manuscript accessibility in different formats ( Pdf, E-pub, Full Text, Audio)

- Unceasing customer service

Track the below URL for one-step submission

https://juniperpublishers.com/online-submission.php 